\title{
Ruxolitinib for Glucocorticoid-Refractory Acute Graft-versus-Host Disease: A Giant Leap-To Start with Baby Steps
}

The study by Zeiser et al. published in the New England Journal of Medicine represents a significant landmark as the first major randomized controlled trial for patients with steroid-refractory-acute graft-versus-host disease (SR-aGVHD). ${ }^{[1]}$ This randomized Phase 3 trial compared ruxolitinib with other available treatment options for SR-aGVHD and found significantly better responses at 28 days and 56 days post transplant. Even with a plethora of options available for second-line treatment of aGVHD, the lack of efficacy data has precluded the recommendation of a preferred second-line agent. Most studies have cited that overlapping response rates, cost, toxicity, and availability in the market are the major factors in choosing the treatment for SR-aGVHD. ${ }^{[2]}$ This study represents the first step in filling these lacunae and in improving our understanding of treating SR-aGVHD.

However, this study raises two important questions, which have to be answered before we can truly endorse ruxolitinib as the de facto option for SR-aGVHD.

First, the heterogeneity in the control arm may falsely amplify the benefit noted with ruxolitinib. The options included in this arm have variable response rates and time to onset of maximal action, making it difficult to standardize this group. In observational studies, many agents used in the control arm have response rates comparable to those seen with ruxolitinib in the present study. For instance, studies with interleukin-2 inhibitors, such as basiliximab and daclizumab, have reported response rates above $60 \%{ }^{[3,4]}$ Similar responses have been noted with methotrexate and etanercept. ${ }^{[5]}$ This is much higher than the overall response rates (39\%) noted in the control arm of this study. In addition, mycophenolate mofetil has not shown any benefit when added to steroids for treating aGVHD, that led to the early closure of the randomized BMT CTN0802 trial due to futility. ${ }^{[6]}$

Second, the use of ruxolitinib in this setting may be inundated with unavoidable pharmacokinetic variables. The presence of diarrhea in GVHD is associated with malabsorption of food and oral drugs. ${ }^{[7]}$ As initial dose finding studies with ruxolitinib have included predominantly Caucasian populations, variability in absorption and metabolism may conceal its true efficacy and toxicity. ${ }^{[8]}$ Ruxolitinib is metabolized by the CYP3A4 enzymes, and over $70 \%$ of its efficacy is attributable to active metabolites. CYP3A4 enzyme activity has been noted to vary with ethnicity and may lead to varying drug effects in different populations. ${ }^{[9]}$

Many treatment modalities for SR-aGVHD, including mesenchymal stem cells, extracorporeal photopheresis, and anti-thymocyte globulin, are beset with formidable toxicity and costs. For ruxolitinib to truly emerge as an evidence-based first-line option for SR-aGVHD, we will need to look at subgroup analyses and comparison with individual second-line modalities. In addition, indigenous pharmacokinetic studies will be vital to assess the absorption and metabolism of this drug in different ethnic populations.

The REACH2 trial is an important landmark. While discussing the same with patients and families, it may help us to highlight ruxolitinib as a new treatment option with comparable or superior efficacy and manageable toxicity. This in itself is a giant leap in this field.

Financial support and sponsorship

Nil.

\section{Conflicts of interest}

There are no conflicts of interest.

\section{Suvir Singh}

Department of Clinical Haematology and Stem Cell Transplantation, Dayanand Medical College, Ludhiana, Punjab, India

Address for correspondence: Dr. Suvir Singh, Department of Clinical Haematology and Stem Cell Transplantation, Dayanand Medical College, Basement, Cancer Building, Ludhiana - 141 001, Punjab, India.

E-mail:suvirs@gmail.com

Submitted: 03-Jun-2020

Revised: 30-Jun-2020

Accepted: 03-Jul-2020

Published: 29-Oct-2020

\section{References}

1. Zeiser R, von Bubnoff N, Butler J, Mohty M, Niederwieser D, Or $\mathrm{R}$, et al. Ruxolitinib for glucocorticoid-refractory acute graft-versus-host disease. N Engl J Med 2020;382:1800-10.

2. Malard F, Huang XJ, Sim JPY. Treatment and unmet needs in steroid-refractory acute graft-versus-host disease. Leukemia 2020;34:1229-40.

3. Schmidt-Hieber M, Fietz T, Knauf W, Uharek L, Hopfenmüller W, Thiel E, et al. Efficacy of the interleukin-2 receptor antagonist basiliximab in steroid-refractory acute graft-versus-host disease. Br J Haematol 2005;130:568-74.

4. Bordigoni P, Dimicoli S, Clement L, Baumann C, Salmon A, Witz F, et al. Daclizumab, an efficient treatment for steroid-refractory acute graft-versus-host disease. Br J Haematol 2006; 135:382-5.

5. Nassar A, Elgohary G, Elhassan T, Nurgat Z, Mohamed SY, Aljurf M. Methotrexate for the treatment of graft-versus-host disease after allogeneic hematopoietic stem cell transplantation. J Transplant 2014;2014:980301.

6. Bolaños-Meade J, Logan BR, Alousi AM, Antin JH, Barowski K, Carter SL, et al. Phase 3 clinical trial of steroids/mycophenolate 
mofetil vs steroids/placebo as therapy for acute GVHD: BMT CTN 0802. Blood 2014;124:3221-7.

7. van der Meij BS, Wierdsma NJ, Janssen JJ, Deutz NE, Visser OJ. If the gut works, use it! But does the gut work in gastrointestinal GvHD? Bone Marrow Transplant 2017;52:466-9.

8. Verstovsek S, Mesa RA, Gotlib J, Levy RS, Gupta V, DiPersio JF, et al. Efficacy, safety and survival with ruxolitinib in patients with myelofibrosis: Results of a median 2-year follow-up of COMFORT-I. Haematologica 2013;98:1865-71.

9. Guttman Y, Nudel A, Kerem Z. Polymorphism in cytochrome P450 3A4 is ethnicity related. Front Genet 2019;10:224.
This is an open access journal, and articles are distributed under the terms of the Creative Commons Attribution-NonCommercial-ShareAlike 4.0 License, which allows others to remix, tweak, and build upon the work non-commercially, as long as appropriate credit is given and the new creations are licensed under the identical terms.

\begin{tabular}{|l|l|}
\hline \multicolumn{2}{|c|}{ Access this article online } \\
\hline Quick Response Code: & Website: \\
& www.ijmpo.org \\
\cline { 2 - 2 } & DOI: \\
\hline
\end{tabular}

How to cite this article: Singh S. Ruxolitinib for glucocorticoid-refractory acute graft-versus-host disease: A giant leap - To start with baby steps. Indian J Med Paediatr Oncol 2020;41:733-4. 